Pacific Journal of 


\title{
MATRIX TRANSFORMATIONS OF SOME SEQUENCE SPACES
}

\author{
K. Chandrasekhara RaO
}

\begin{abstract}
One of the important investigations in the theory of summability is that of finding necessary and sufficient conditions on an infinite matrix in order that the matrix should transform one (complex) sequence space into the same or another sequence space. In this note some such theorems are given.
\end{abstract}

Let

$C_{0}=$ the space of null sequences;

$C=$ the space of convergent sequences;

$\Gamma=$ the space of sequences $x=\left\{x_{p}\right\}$ such that $\left|x_{p}\right|^{1 / p} \rightarrow 0$, as $p \rightarrow \infty$. The space $\Gamma$ can be regarded as the space of all integral functions $f(z)=\sum_{p=1}^{\infty} x_{p} z^{p}$;

$\Gamma^{*}=$ the space of sequences $s=\left\{s_{p}\right\}$ such that the sequence $\left\{\left|s_{p}\right|^{1 / p}\right\}$ is bounded. $\Gamma^{*}$ may also be considered as the space conjugate to $\Gamma$ regarded as the space of integral functions $f(z)=\sum_{p=1}^{\infty} x_{p} z^{p}$. Each continuous linear functional $U \in \Gamma^{*}$ is of the form $U(f)=$ $\sum_{p=1}^{\infty} s_{p} z_{p}$.

Let $A=\left(a_{n p}\right),(n, p=1,2, \cdots)$, be an infinite matrix of complex elements. The $A$ transform of $x=\left\{x_{p}\right\}, y=\left\{y_{n}\right\}$ is the sequence defined by the equations

$$
y_{n}=\sum_{p=1}^{\infty} a_{n p} x_{p},(n=1,2, \cdots) .
$$

Here $y=\left\{y_{n}\right\}$ and $x=\left\{x_{p}\right\}$ are complex sequences. Similarly, the $A$ transform of $s=\left\{s_{p}\right\}, t=\left\{t_{n}\right\}$ is the sequence defined by the equations

$$
t_{n}=\sum_{p=1}^{\infty} a_{n p} s_{p},(n=1,2, \cdots) .
$$

Here also $t=\left\{t_{n}\right\}$ and $s=\left\{s_{p}\right\}$ are both complex sequences.

The following theorems are true:

THEOREM I. Let (1) hold. In order that $\left\{y_{n}\right\}$ should belong to $\Gamma$ whenever $\left\{x_{p}\right\}$ belongs to $C_{0}$, it is necessary and sufficient that

$(\mathrm{I}, 1)$ the sequence $\left\{\theta_{n}\right\}$ is a null sequence, where

$$
\theta_{n}=\left(\sum_{p=1}^{\infty}\left|a_{n p}\right|\right)^{1 / n},(n=1,2, \cdots) .
$$

Theorem I holds even if $C_{0}$ is replaced by $C$. 
THEOREM II. Let (1) hold. In order that $\left\{y_{n}\right\}$ should belong to $\Gamma^{*}$ whenever $\left\{x_{p}\right\}$ belongs to $C$, it is necessary and sufficient that

(II, 1) the sequence $\left\{\theta_{n}\right\}$ is bounded, where $\theta_{n},(n=1,2, \cdots)$, are given by (3).

THEOREM III. Let (1) hold. In order that $\left\{y_{n}\right\}$ should belong to $C$ whenever $\left\{x_{p}\right\}$ belongs to $\Gamma$, it is necessary and sufficient that

(III, 1) $\left|a_{n p}\right|^{1 / p} \leqq M$ independently of $n, p$;

(III, 2) $\lim _{n \rightarrow \infty} a_{n p}=a_{p}$ exists for each fixed $p$.

THEOREM IV. Let (2) hold. In order that $\left\{t_{n}\right\}$ should belong to $C$ whenever $\left\{s_{p}\right\}$ belongs to $\Gamma^{*}$, it is necessary and sufficient that

$(\mathrm{IV}, 1)$ the sequence $\left\{f_{n}(z)\right\}$ of integral functions

$$
f_{n}(z)=\sum_{p=1}^{\infty} a_{n p} z^{p},(n=1,2, \cdots),
$$

is uniformly bounded on every compact set (of the complex plane);

$(\mathrm{IV}, 2)=(\mathrm{III}, 2) \lim _{n \rightarrow \infty} a_{n p}=a_{p}$ exists for each fixed $p$.

Theorem V. Let (1) hold. In order that $\left\{y_{n}\right\}$ should belong to $\Gamma^{*}$ whenever $\left\{x_{p}\right\}$ belongs to $\Gamma$, it is necessary and sufficient that

$(\mathrm{V}, 1)\left|a_{n p}\right|^{1 /(n+p)} \leqq M$ independently of $n, p$.

Theorem VI. Let (2) hold. In order that $\left\{t_{n}\right\}$ should belong to $\Gamma$ whenever $\left\{s_{p}\right\}$ belongs to $\Gamma^{*}$, it is necessary and sufficient that

(VI, 1) $\left|f_{n}(z)\right|^{1 / n} \rightarrow 0$, as $n \rightarrow \infty$, uniformly on every compact set (of the complex plane), where $\left\{f_{n}(z)\right\}$ is the sequence of integral functions $f_{n}(z)$ given by (4).

THeOREM VII. Let (1) hold with $a_{i j}=0$ for $i>j$. In order that $\left\{y_{n}\right\}$ should belong to $\Gamma$ whenever $\left\{x_{p}\right\}$ belongs to $\Gamma$, it is necessary and sufficient that

(VII, 1) $\left|a_{n p}\right|^{1 / p} \leqq M$ independently of $n, p$.

The matrix transformation of $\Gamma^{*}$ into $\Gamma^{*}$ was studied by Heller [6].

The sufficiency, in each case is a straightforward calculation. The necessity of any of the above conditions is proved by taking special sequences, and constructing sequences to contradict the given condition, or by using Functional Analysis. Indeed, to prove the necessity of (III, 1), let $U_{n}(x)=y_{n}=\sum_{p=1}^{\infty} a_{n p} x_{p},(n=1,2, \cdots)$, for each fixed $x=\left\{x_{p}\right\} \in \Gamma$. Then $\left\{U_{n}(x)\right\}$ represents a sequence of continuous linear functionals on $\Gamma$ ([4], Th. 4). Here $\left\{\left|a_{n p}\right|^{1 / p}\right\}$ is bounded for each fixed $n$. Since $\left\{y_{n}\right\} \in C$, it follows that $\varlimsup_{n \rightarrow \infty}\left|U_{n}(x)\right|<\infty$ for each fixed $x \in \Gamma$. Define for each $x \in \Gamma,|x|=$ upper bound $\left(\left|x_{p}\right|^{1 / p}, p \geqq 1\right)$. 
Then for $x, x^{\prime} \in \Gamma,\left|x-x^{\prime}\right|$ defines a metric or distance in $\Gamma$. With the metric, $\Gamma$ is a complete metric space. Therefore, by Theorem 11 of ([1], p.19), there is a closed sphere $S$ and a fixed number $M$ such that

$$
\left|U_{n}(x)\right| \leqq M \text { for } x \in S \text { and all } n \geqq 1 \text {. }
$$

Take the sphere $S$ as $|x| \leqq d$. Set $x_{p}=(d / 2)^{p}$ and $x_{j}=0$ for all $j \neq p$ so that $|x| \leqq d / 2$ and hence $x=\left\{x_{p}\right\} \in S \subset \Gamma$. Then, by (5), it at once follows that

$$
\left|U_{n}(x)\right|=\left|a_{n p}(d / 2)^{p}\right| \leqq M .
$$

That is, $\left|a_{n p}\right|^{1 / p} \leqq M^{1 / p}(2 / d)<2 m(M) / d$ where $m(M)=\max (1, M)$. This proves the necessity of (III, 1 ).

A similar proof applies to condition (VII, 1).

Finally, I thank Professor V. Ganapathy Iyer for his help and guidance. I also thank the referee for drawing my attention to the papers of Sheffer [10] and Zeller [14], and other useful comments. Conditions of Theorems V, VI and VII neither include nor are included in Sheffer's conditions. However, $\Gamma$ and $\Gamma^{*}$ are included in the spaces considered by Sheffer. Sheffer [10] and Zeller [14] also dealt with the spaces of all power series with a certain minimal radius of convergence.

\section{BIBLIOGRAPHY}

1. S. Banach, Théorie des opérations linéaires, Monogr. Mat., Warsaw, (1932).

2. R. G. Cooke, Infinite matrices and sequence spaces, Macmillan, London, 1950.

3. P. Dienes, The Taylor series, Oxford, 1931.

4. V. Ganapathy Iyer, On the space of integral functions-I, J. Indian Math. Soc.

(2) 12 (1948), 13-30.

5. G. H. Hardy, Divergent series, Oxford, 1949.

6. I. Heller, Contributions to the theory of divergent series, Pacific J. Math. 2 (1952), 153-177.

7. T. Kojima, On generalized Toeplitz's theorems on limit and their applications, Tôhoku Math. J. 12 (1917), 291-326.

8. K. Knopp, und G. G. Lorentz, Beiträge zur absoluten Limitierung, Arch. Math. 2 (1949), 10-16.

9. I. Schur, Über lineare Transformationen in der theorie der unendlichen Reihen,

J. Reine. Angew. Math. 151 (1920), 79-111.

10. I. M. Sheffer, Systems of linear equations of analytic type, Duke Math. J. 11 (1944), 167-180.

11. O. Szász, Introduction to the theory of divergent series, University of Cincinnati, Cincinnati, Ohio, 1946.

12. O. Toeplitz, Über allgemeine lineare Mittlebildungen, Prace Math. Fiz. 22 (1911) 113-119.

13. A. Wilansky, Functional analysis, Blaisdell, New York, 1964.

14. K. Zeller, Transformationen des Durchschnitts und der Vereinigung von Folgen- 
raumen, Math. Nachr. 10 (1953), 175-177.

15. - Matrix transformationen von Folgenraumen, Uni. Roma. Ist. Naz. Alta. Mat. Rend. Mat. Appl. (5) 12 (1954), 340-346.

16. Theorie der Limitierungsverfahren, Springer-Verlag, Berlin-GöttingenHeidelberg, 1958.

Received January 8, 1968, and in revised form March 3, 1969.

ANnamalai University

ANNAMALAINAGar, INDIA 


\section{PACIFIC JOURNAL OF MATHEMATICS}

\section{EDITORS}

H. ROYDEN

Stanford University

Stanford, California

Richard Pierce

University of Washington

Seattle, Washington 98105
J. DUGUNDJI

Department of Mathematics

University of Southern California

Los Angeles, California 90007

BASIL GORDON

University of California

Los Angeles, California 90024

\section{ASSOCIATE EDITORS}
E. F. BECKENBACH
B. H. NEUMANN
F. WOLF
K. YosHIDA

\section{SUPPORTING INSTITUTIONS}

UNIVERSITY OF BRITISH COLUMBIA

CALIFORNIA INSTITUTE OF TECHNOLOGY

UNIVERSITY OF CALIFORNIA

MONTANA STATE UNIVERSITY

UNIVERSITY OF NEVADA

NEW MEXICO STATE UNIVERSITY

OREGON STATE UNIVERSITY

UNIVERSITY OF OREGON

OSAKA UNIVERSITY

UNIVERSITY OF SOUTHERN CALIFORNIA
STANFORD UNIVERSITY

UNIVERSITY OF TOKYO

UNIVERSITY OF UTAH

WASHINGTON STATE UNIVERSITY

UNIVERSITY OF WASHINGTON

*

AMERICAN MATHEMATICAL SOCIETY CHEVRON RESEARCH CORPORATION TRW SYSTEMS

NAVAL WEAPONS CENTER 


\section{Pacific Journal of Mathematics}

\section{Vol. 31, No. $1 \quad$ November, 1969}

James Burton Ax, Injective endomorphisms of varieties and schemes........

Richard Hindman Bouldin, A generalization of the Weinstein-Aronszajn

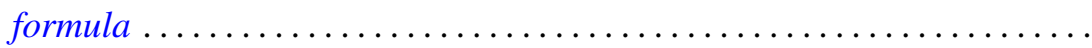

John Martin Chadam, The asymptotic behavior of the Klein-Gordon equation with external potential. II ...............................

Rina Hadass, On the zeros of the solutions of the differential equation

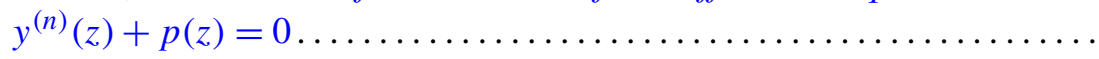

John Sollion Hsia, Integral equivalence of vectors over local modular lattices. II .............................................

Robert Hughes, Boundary behavior of random valued heat polynomial

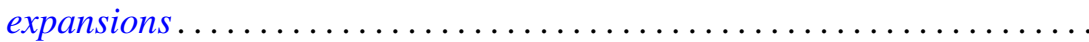

Surender Kumar Jain, Saad H. Mohamed and Surjeet Singh, Rings in which every right ideal is quasi-injective .........................

T. Kawata, On the inversion formula for the characteristic function .........

Erwin Kleinfeld, On right alternative rings without proper right ideals......

Robert Leroy Kruse and David Thomas Price, On the subring structure of

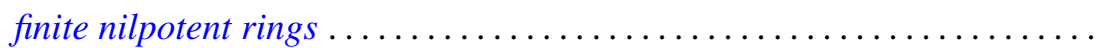

Marvin David Marcus and Stephen J. Pierce, Symmetric positive definite multilinear functionals with a given automorphism. .

William Schumacher Massey, Pontryagin squares in the Thom space of a bundle...

William Schumacher Massey, Proof of a conjecture of Whitney ...

John William Neuberger, Existence of a spectrum for nonlinear transformations

Stephen E. Newman, Measure algebras on idempotent semigroups ...

$\mathrm{K}$. Chandrasekhara Rao, Matrix transformations of some sequence spaces

Robert Bruce Schneider, Some theorems in Fourier analysis on symmetric

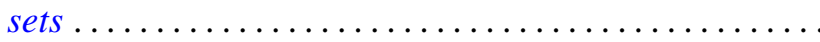

Ulrich F. K. Schoenwaelder, Centralizers of abelian, normal subgroups of hypercyclic groups...

Jerrold Norman Siegel, $G$-spaces, $H$-spaces and $W$-spaces

Robert Irving Soare, Cohesive sets and recursively enumerable Dedekind cuts...

Kwok-Wai Tam, Isometries of certain function spaces .... . .

Awadhesh Kumar Tiwary, Injective hulls of semi-simple modules over regular rings ....

Eldon Jon Vought, Concerning continua not separated by any nonaposyndetic subcontinuum .................... 